\title{
Ciência, Poesia e Literatura: a Geologia Estética na obra do escritor romântico José de Alencar
}

\author{
Science, Poetry and Literature: Aesthetic Geology in the work of the romantic writer José de Alencar \\ Soraya Almeida \\ Departamento de Geociências, Setor de Petrologia UFRURAL/RJ, Seropédica, RJ. - Salmeida1966@gmail.com
}

ABSTRACT: José de Alencar, a leading name of the romantic literary movement in Brazil, lived between 1829 and 1877, a period in which geology was recognized as an independent science, and in which it became a subject of interest outside the scientific community. The writer was not insensitive to geological questions, and his works show several examples of aesthetic geology. The use of geological elements in his novels becomes more expressive after his marriage with Georgina Cochrane, who was part of a Scottish family with a solid literary and scientific background, and whose members were admirers of the mountains. The use of volcanoes as metaphors for hidden feelings and the personification of rocks and mountains are the most expressive poetic use of geological features in his novels. His gloomy views about rocks and mountains are in tune with the perception manifested by Thomas Burnet and the British romantic poets. In Alencar's books, granite is "the rock" par excellence, and like Goethe, the writer shows displeasure with the plutonic model advocated by Hutton and Lyell.

\author{
Manuscrito: \\ Recebido: 01/06/2017 \\ Corrigido: 25/09/2017 \\ Aceito: 26/09/2017
}

Citation: Almeida S. 2017. Ciência, Poesia e Literatura: a Geologia Estética na obra do escritor romântico José de Alencar.Terræ Didatica, 13(3):219-234. < http://www.ige.unicamp.br/ terraedidatica/ $>$.

Keywords: José de Alencar, aesthetic geology, romanticism, history of geology, Brazilian literature

\section{Introdução}

Nascido em Messejana, Ceará, no ano de 1829, o escritor brasileiro José de Alencar foi autor de vários ensaios, romances, peças teatrais, crônicas e uma autobiografia, consagrando-se como um dos grandes nomes da literatura romântica brasileira e reconhecido por muitos como o fundador da literatura de caráter nacional. Primogênito dentre doze filhos do padre José Martiniano Pereira de Alencar e de sua prima, Ana Josefina de Alencar, o escritor pertencia a uma família de grande influência política. Seu pai foi senador e presidente da Província do Ceará, mudando-se com a família para o Rio de Janeiro em 1838. Aos quatorze anos, José de Alencar se separou da família para residir em uma república de estudantes na cidade de São Paulo, onde cursou preparatórios para o Curso de Direito, concluído em 1850. No período em que viveu em São Paulo criou, em parceria com seus colegas do curso, a revista semanal Ensaios Literários, onde foram publicadas suas primeiras composições. Sua estreia como folhetinista se deu em 1854 no Correio
Mercantil com a seção Ao Correr da Pena. Dois anos depois, assumiu o cargo de redator chefe do Diário do Rio de Janeiro, onde estreou como novelista com o romance Cinco Minutos. Foi nesse mesmo diário que Alencar publicou, em 1857, O Guarani, obra que o tornou prestigiado. Em 1864, Alencar casou-se com Georgiana Augusta Cochrane, filha do médico homeopata escocês Thomas Cochrane, com quem teve seis filhos. A carreira literária de José de Alencar, morto em 1877, foi entremeada com atuações na política e no funcionalismo público: foi conselheiro na Secretaria de Negócios da Justiça e Consultor de Negócios do Governo Imperial, elegendo-se deputado estadual pelo Ceará por quatro vezes e assumindo o Ministério da Justiça sob o governo de D. Pedro II, em 1868, cargo que ocupou até 1870 (Alencar 2005, Broca 1981, Viana Filho 1979).

Autor de extrema importância na história da literatura brasileira, José de Alencar teve o conjunto de sua obra analisada por biógrafos, críticos, admiradores e acadêmicos. Vários aspectos da obra alencariana são abordados nesses trabalhos. Entre- 
tanto, o uso estético de elementos geológicos em seus livros é um tema ainda não discutido, mas não menos importante da obra do escritor, como será demonstrado neste artigo.

\section{Interfaces entre Geologia e Literatura}

A partir do século dezessete, com o estabelecimento da Nova Ciência que trazia consigo uma proposta mais racionalista na forma de divulgação de dados e teorias, a união entre o que hoje conceituamos como "literatura" e "ciência" começou a se romper de forma gradual pois, até então, não existia uma divisão precisa entre estes dois ramos de produção intelectual. Obras que remontam à Antiguidade, como Metamorfose, de Ovídio, entrelaçavam história, fantasia e dados sobre a natureza em uma só expressão literária. A união de disciplinas é desmontada pela obra Novum Organum de Francis Bacon, publicada em 1620 (Bacon 1999) que reconhece três diferentes tipos de ciência: Poesia (ou Ciência da Imaginação), História (ou Ciência da Memória) e Filosofia (ou Ciência da Razão). $\mathrm{Na}$ nova organização, a ciência muda sua forma e função, adquirindo linguagem independente e passando a ser regida por novas regras. Mas a separação, contudo, foi lenta. Ciência e literatura ainda compartilharam linguagens e influenciaram-se mutualmente nos séculos dezoito e dezenove. O poema Jardim Botânico, publicado em 1791 pelo naturalista Erasmus Darwin, é um exemplo dessa combinação literária (Darwin 1825). Discorrendo sobre várias questões científicas por meio da poesia, a obra dedica vários versos à mineração $\mathrm{e}$ à geologia, incorporando ideias de Hutton, com quem Erasmus Darwin se correspondia (Heringman 2004). Assim como no livro de Darwin, temas relacionados à geologia passaram a ser abordados de forma cada vez mais expressiva na literatura poética e ficcional ao longo do século dezenove, pois nesse período o estudo da Terra se tornou relevante na vida econômica e social da Europa em função da grande demanda por ferro e carvão, resultante da Revolução Industrial, da descoberta de fósseis de animais extintos e do surgimento de teorias que revelavam uma Terra misteriosa, até então desconhecida. Novelas, contos, peças de teatro e charges satíricas tendo geologia ou geólogos como tema passaram a ser frequentes e as novas teorias eram compreendidas como elementos estéticos pelos românticos, especialmente entre os poetas. O passado revelado pela geologia era um mun- do sublime, assustador e poético. Palavras como "convulsão", "revolução", "abismo", "forças subterrâneas", "matéria primitiva", "granito" e "lava" tornaram-se comuns tanto ao universo científico como ao mundo artístico. São numerosos os exemplos de influência mútua. Foi por meio do Jardim Botânico, de Erasmus Darwin, que as teorias huttonianas influenciaram a poesia de Willian Blake que, como ilustrador, produziu as imagens do livro de Darwin. Além de Blake, vários outros poetas, como Goethe, Wordsworth, Percy Shelley e Lord Byron, geraram composições que resultavam do exercício da geologia (Nicolson 1997, Heringman 2004). Também na prosa, conceitos ou personagens relacionados à geologia passaram a ser comuns. Esses são encontrados nas obras de autores populares como Walter Scott, Jane Austen, Flaubert, Charles Dickens, Júlio Verne, James de Mille, George Eliot e Samuell Butler e, segundo O'Connor (2007), Principles of Geology, publicado por Charles Lyell a partir de 1830, obteve grande sucesso entre não-geólogos graças à utilização de linguagem literária extremamente elegante. A visão do tempo apresentada por Lyell em Principles foi considerada pelo poeta americano Edward Fitzgerald como "mais maravilhosa" do que as concepções de Dante e Milton (Cadburry 2000).

Enquanto a geologia exercia influência sobre a literatura poética e ficcional, os geólogos incorporavam um estilo poético de descrição ou faziam uso de citações dos poetas mais populares em suas obras. Trechos de Byron são quase onipresentes em livros de geologia do século dezenove; Buckland (2013) demonstra como os geólogos mais proeminentes da época eram leitores de Walter Scott e se espelhavam na literatura do escritor escocês na composição de seus textos científicos.

Nicolson (1997) comprova que a influência da geologia no Movimento Romântico não resultou de experiências individuais, mas sim de uma cultura geral que se desenvolveu concomitantemente à filosofia natural. A influência também é observada na obra de José de Alencar.

\section{Elementos geológicos na obra de José de Alencar}

\section{Personificação}

O uso estético de elementos geológicos já é constatado naquele que seria, segundo o próprio Alencar, seu primeiro romance, Os Contrabandis- 
tas. Escrito quando o autor tinha quinze anos de idade, o manuscrito nunca publicado foi quase totalmente destruído por um hóspede da família que teria utilizado suas folhas para acender cigarros (Alencar 2005). Apenas algumas páginas do romance foram preservadas, entre as quais parte do primeiro capítulo, cujo trecho, apresentado a seguir, é transcrito por Viana Filho (1970). Nele, a Pedra da Gávea, no Rio de Janeiro, é visualizada como um monstro sombrio:

O navio que vem de largo em demanda do porto do Rio de Janeiro divisa ao longe nas oscilações do horizonte uma sombra negra, a princípio indecisa, que vai tomando formas mais distintas, e retraça o vulto enorme de um monstro marinho, estendendo sobre as águas seu dorso escamoso. É o monte da Gávea.

A personificação de um elemento da paisagem em um ser monstruoso é encontrada novamente em sua primeira novela impressa, Cinco Minutos (Alencar 1970a), na qual, por meio de uma dupla metáfora, Alencar transmuta um barco, elemento não natural na paisagem, em um monstro marinho que, por sua vez, expele fumaça e ruge como uma cratera vulcânica:

[...] e o monstro marinho, rugindo corno uma cratera, vomitando fumo e devorando o espaço com os seus flancos negros, lançou-se.

Em ambas as obras a transfiguração da rocha em ser vivo, ocorre como uma percepção ligeira da paisagem mas, em O Gaúcho (Alencar 1970b), a personificação confere impacto dramático a narrativa. Nele, a caverna na qual está preso Juca, um potrinho ferido, não é apenas uma rocha, mas um animal com órgãos internos, possuidor de boca, garganta, ventre, saliva e uma vontade própria que o leva a devorar sua presa:

[...] o terrado declinava e abrupto sumia-se por funda barranca; era aí o ventre da caverna a que a fenda servia apenas de glote. [...] Era difícil a entrada, pela angústia da passagem, que formava a laringe da caverna; a garganta já era estreita e sinuosa; mas ali duas cartilagens do rochedo cerravam o canal. A saliva que segregavam as porosidades calcárias do granito, umedecia todo esse tubo, e o forrava de um muco limoso. Compreendia-se bem como a caverna devorara tão rapidamente o potrinho. A imitação da jiboia o envolvera da baba, para que resvalasse ao longo da garganta.
Essa rocha transfigurada em réptil não é compatível com a ideia da Terra como um organismo vivo que nutre a natureza, mas sim com a percepção sombria de Thomas Burnet expressa em Sacred Theory of the Earth (Burnet 1961). Publicada pela primeira vez em 1681, a obra teve forte influência no movimento romântico britânico nos dois séculos seguintes (Nicolson 1997).

Flankin Távora em Cartas a Cincinato, publicadas entre 1871 e 1872, critica de forma contundente a imprecisão científica de José de Alencar no que diz respeito à flora e fauna, expondo trechos inverossímeis de $O$ Gaúcho e acusando o autor de compor paisagens irreais por desconhecer o cenário geográfico onde passam seus romances (Távora 2011). Tal imprecisão pode ser detectada na atribuição de "porosidade calcária" ao granito, no trecho destacado. Para Proença (1966), contudo, as incorreções de Alencar resultavam não de ignorância sobre os temas abordados, mas de uma liberdade poética comum entre os românticos.

A imagem de um ofídio é mais uma vez evocada por José de Alencar em O Tronco do Ipê (Alencar 1970c), ao descrever a relação entre o Rio Paraíba do Sul e um trecho da Serra do Mar em terras fluminenses:

Às vezes tardo e indolente, outras rápido e estrepitoso com a crescente das águas que o entumeciam, assemelhava-se o Paraíba na calma, como na agitação, a uma píton antediluviana coleando através da antiga selva brasileira.

Esse extrato é proveniente da primeira página do romance e remete à abertura do primeiro capítulo de $A$ Casa Soturna de Charles Dickens, na qual a imagem de um megalossauro circulando pelas ruas de Londres é usada pelo autor inglês para ilustrar os efeitos causados pelas reformas urbanas levadas a efeito na época (Dickens 1986). O termo antediluviano no período Vitoriano designava formações rochosas ou fósseis de seres que teriam existido anteriormente ao Dilúvio; em O Tronco do Ipê, Alencar o utiliza para exprimir a passagem de uma grande extensão do tempo, no qual os elementos da paisagem permanecem constantes, apesar da instabilidade sazonal do Rio Paraíba.

Alencar não se restringe à personificação das rochas e montanhas em animais, mas estas também exibem características humanas. Em Sonhos D'Ouro (Alencar 1970d), o Morro do Corcovado é um gigante, mas um gigante apequenado diante das dimensões da Serra do Mar 
A nossos pés, o gigante da pedra, o prócero Corcovado, que o nauta em demanda da barra antolha-se como o guarda desse Jardim das Hespérides e daqui parece agachado, como um anão, à base da grande montanha que nos serve de pedestal.

Em O Tronco do Ipê, um fragmento da Serra do Mar mimetiza um tropeiro, tipo humano frequente nas estradas que ligavam o litoral carioca ao interior do país no período em que se passa o romance.

De longe e visto de perfil, o rochedo parecia um tropeiro, derreado sobre o pescoço da mula e carregando às costas sua maca de viagem.

Alencar apresenta uma proposta inversa em $O$ Gaúcho. Enquanto a rocha reflete a vida ao mimetizar o tropeiro, o orgânico se torna assustador se petrificado:

Pouco falta para a madrugada. A noite arrasta-se pesada e lúgubre no meio de uma calma assustadora, que estranha a natureza. Nem um sopro de aragem bafeja a terra, encandecida ainda pelo intenso calor do sol [...] No horizonte opaco se debuxam as cúpulas das árvores, semelhantes a massas de granito.

Em algumas circunstâncias, as rochas não constituem apenas uma representação de seres vivos, mas desempenham um papel quase humano, como em O Tronco do Ipê, onde são vistos como que companheiros de infância de Mário:

Mário conhecia todo o rochedo pelo direito como pelo avesso; tinha subido aos mais altos e abruptos dos píncaros; e descera às profundas cavernas e escuras fendas abertas na rocha. Sabia a forma e o tamanho de cada uma dessas criaturas de pedra; todas tinham para ele uma figura, uma atitude e um nome. Estudara até os seus costumes. Sabia a hora em que apanhavam sol, ou se cobriam de sombras; $[\ldots]$

Com o propósito de compreender a razão da morte de seu pai, tragado pelas águas do rio, Mário estuda cuidadosamente a estrutura do Boqueirão, mas a natureza, como se tivesse vontade própria, se recusa a dar-lhe uma resposta sobre as circunstâncias do desaparecimento do corpo:

Toda essa luta porém fora inútil. O lago, o rochedo, a floresta, se conservaram mudos. / Não obstante ele continuava a lutar. Achava-se justamente no lugar mais estreito do remoinho, no que se poderia bem chamar a faringe do abismo. Era aí o foco do turbilhão; era aí que a onda angustiada pela rocha, se precipitava com ímpetos medonhos nas profundezas da caverna.

Sombria, monstruosa, devoradora, pesada, repulsivas, lúgubre, escura, angustiante, indiferentes ao sofrimento humano: na personificação das rochas por Alencar predominam conotações negativas e mesmo escatológicas. Se em O Gaúcho as infiltrações são comparadas a saliva, em Til, ouro é comparado a fezes:

Daí partiam pelo caminho d'água as expedições que os arrojados paulistas levavam às regiões desconhecidas do Cuiabá, descortinando o deserto, e rasgando as entranhas da terra virgem, para arrancar-lhe as fezes, que o mundo chama ouro e comunga como a verdadeira hóstia.

e lavas são relacionadas a vômito:

Foi rápido, porém, o deslumbramento. Debruçando-se no peitoril e descobrindo o foco do incêndio que vomitava labaredas como a cratera de um vulcão, o fazendeiro compenetrou-se imediatamente da realidade.

Mesmo ao visualizar as rochas como símbolo de força em Ubirajara (Alencar 1970e), essa imagem é acompanhada de melancolia. O jovem guerreiro é percebido como um rochedo sombrio enquanto o velho chefe Guaribui, um rochedo negro:

O tapuia rugiu; mas seus olhos viam o mar dos guerreiros araguaias que o cercava, e na frente o grande vulto de Ubirajara, semelhante ao rochedo sombrio e imóvel do meio dos borbotões da cachoeira. / O semblante do velho chefe cobriu-se de um sorriso, como o negro rochedo sobre o qual desliza um raio de luar.

A imagem difundida por Burnet das montanhas como deformidades patológicas, comum na poesia romântica britânica no final do século dezoito, também é observada em O Gaúcho. Ao descrever a mudança de orientação da Serra do Mar, de nordeste-sudoeste, ao longo da costa, para oeste, em direção a cidade de São Pedro, Alencar utiliza o termo "bossa":

Cruzando a coxilha grande, que atravessa a província de São Pedro, se alonga a serra do mar, como a bossa granítica daquele espinhaço. 


\section{Sentimentos}

A personificação de elementos geológicos é, entretanto, menos frequente na obra de Alencar do que sua utilização como expressão de sentimentos ou do caráter dos personagens.

A ira do Capitão-Mor Gonçalo Pires Campelo, diante da desobediência de Arnaldo Loureiro à sua ordem de trazer o velho Jó à sua presença, se manifesta em O Sertanejo (Alencar 1970f), como uma atividade vulcânica:

Foi então que a ira terrível do velho fez explosão, estalando como a cratera de um rochedo vulcânico ao arremessar a lava.

No ritual destinado ao sacrifício de Peri, feito prisioneiro entre os Aimorés, em O Guarani (Alencar, 1970g), o desejo de vingança emana dos olhos do cacique como a luz de um vulcão:

Tinha o rosto pintado de uma cor esverdeada e oleosa, e o pescoço cingido de uma coleira feita com as penas brilhantes do tucano; no meio desse aspecto horrendo os seus olhos brilhavam como dois fogos vulcânicos no seio das trevas.

Em As Minas de Prata (Alencar 1970h,i,j), a ambição do padre Molina é simbolizada por um vulcão interior que se esconde sob uma face fria de mármore:

Aquela fronte larga e proeminente, cobrindo como uma abóbada de mármore os olhos fundos, onde a pupila negra brilhava na sombra com reflexos de um fogo vulcânico nas trevas da noite; $[\ldots]$

O mesmo Molina, ao pregar em Salvador, mais uma vez deixa transparecer sua verdadeira personalidade, oculta pela face solene:

Os olhos fugidos pelas órbitas, pareciam submergir-se nas profundezas daquele vasto espírito, para arrancar dali, como das entranhas de um vulcão, a lava incandescente do olhar.

Ao descrever as origens do jesuíta, Alencar utiliza estilo diverso do tom épico predominante no livro; a narrativa dramática, até então dominante, adquire cunho satírico, numa mudança brusca, ao feitio de Dickens. Molina é apresentado, então, como um jovem espanhol errante, despreocupado e inconsequente, que se envolve em situações cômi- cas. Mas mesmo nessa nova forma de narrativa, a lava interior do futuro jesuíta, sua "chama fugace", está presente e se transforma em "labareda de um incêndio" após Molina ter aulas de cosmografia. Ao perceber o poder advindo do saber, Molina se transforma em um homem calculista, disposto a atingir seus objetivos a qualquer custo. Com o conhecimento adquirido, suas ideias entram em erupção:

O moço escolar devorou o livro; quando o terminou, tinha na cabeça um vulcão de ideias; corriam lavas do cérebro em ebulição; dos olhos incendidos saltavam chispas de fogo.

Não apenas Molina, mas outros personagens de As Minas de Prata apresentam manifestações de um fogo interno. Inesita, determinada a suicidar-se quando obrigada a se casar contra a própria vontade, oculta seus sentimentos, reprimidos como lavas aprisionadas sob a superfície. Alencar utiliza o verbo "vulcanizar" para expressar a intensidade desses sentimentos e, mais uma vez, são os olhos do personagem que permitem vislumbrar a combustão interna:

Contemplando-a, percebia-se a violência que ela empregava para reter dentro de si uma alma que esforçava por irromper e vazar-se; mas não obstante a sua resistência de vez em quando desprendiam-se chispas ardentes, que incendiavam o olhar e fulgiam no sorriso. Nunca maior paixão e mais possante cólera vulcanizou um coração de mulher.

Seu par romântico, Estácio, por sua vez, ao aparecer subitamente defronte ao amigo Cristóvão, que naquele momento considerava um traidor, tem sua dor representada pela imagem de um vulcão:

O sombreiro abatido ao chão por um gesto rápido, mostrou o lívido semblante de Estácio, e especialmente a fronte vasta que esmagava com o peso do seu vulcão aquele busto já vergado pela dor.

Também no romance Til (Alencar 19701), o fogo vulcânico é utilizado para figurar sentimentos e desejos ocultos. Jão Fera, quando caçado por um grupo de homens, ao esconder-se em sua caverna em companhia de Berta, luta internamente contra a atração física que sente pela jovem. A ansiedade contida é revelada pelo assassino quando seu olhar encontra o de Berta: 
Esta exclamação, a arrancara dos lábios da menina o espanto causado pelo aspecto medonho do Bugre que voltara-se arrebatadamente e cravara nela um olhar ardente e sombrio, como a cratera de um vulcão.

A imagem que se segue é ainda mais contundente. Ao dominar seu desejo, Jão Fera torna-se uma montanha gelada que resiste à lava corrente, agora representada pelo corpo da jovem:

A terra abrasada pelo sol exalava o bafo incandescente de uma fornalha; e contudo sentia Jão Fera correr-lhe pela medula um calafrio. $\mathrm{O}$ contato do corpo gentil de Berta queimava-lhe ainda o peito amplo; mas era a lava que ferve no meio dos píncaros gelados dos Andes.

O desejo também é transfigurado em lava em O Gaúcho. Ao contemplar o céu em meio a uma tempestade, Manuel Canho vislumbra os olhos de Catita que, por seu turno, envolvem sua alma em lava diabólica:

[...] e do seio da luz celeste desprendiam-se duas centelhas que lhe traspassavam a alma e embebiam nela uma lava satânica. Eram os olhos de Catita.

Aqui, Alencar faz uso do mesmo recurso de transmutação dupla empregado em Cinco Minutos, ao evocar a imagem da lava a partir de uma primeira representação poética de relâmpagos.

A imprudência da mesma Catita em dedicar sua afeição a alguém incapaz de corresponder a esse amor seria análoga à aventura de entrar em contato com um vulcão. Assim como gera fascínio, o vulcão e o amor podem levar a um final trágico:

O amor de Catita, de escravo que era, tornou-se verdadeiro tirano. Submeter essa alma que a tinha dominado outrora aos mínimos caprichos; fazer do gaúcho terrível, que os mais bravos temiam, um brinco de moça faceira, e folgar com as paixões violentas daquele coração como uma criança imprudente com as lavas de um vulcão, foram os deleites dessa afeição.

Lava como expressão de desejo novamente é observada em Sonhos D'Ouro. O olhar de Ricardo para Guida não é apenas ardente, mas capaz de fixar sua forma como as cinzas de Pompéia e Herculano:

Os olhos de Guida e Ricardo se encontraram.

Reconhecendo-a, o moço envolveu-a com o olhar, um desses olhares ardentes e profundos, que embebem em si os objetos, como um molde, para depois vazá-los dentro d'alma. Olhar de poeta ou de artista, que esculpe na memória estátuas, os relevos e arabescos da natureza; donde os copia depois a imaginação em poemas, em harmonias, em raios de luz. Esse olhar tem alguma coisa do cinzel que talha, e da lava ardente que se coalha e vitrifica sobre os objetos.

E se a lava representa ambição, desejo, paixão e revolta, o sofrimento profundo é comparado a abalos sísmicos em $O$ Tronco do Ipê. A decepção amorosa de Alice teria pequena dimensão diante da dor de Mário, que havia perdido o pai na primeira infância e suspeitava que seu benfeitor fosse o assassino. Assim como os terremotos subvertem camadas, grandes desgostos subverteriam a alma:

Ver murchar a esperança que nosso coração afagou desde a infância, é triste sem dúvida, mas não se compara com os transes da subversão que dilacera uma alma, como o terremoto revolve o solo.

Ao abordar essa questão, Alencar remete a um tema sensível aos românticos: a inversão estratigráfica. Na visão romântica, tal inversão simbolizava a desordem, pois permitia rochas mais antigas posicionarem-se acima das mais jovens. Por fim, a desconfiança por parte de Mário de que seu pai tivesse sido assassinado é "intempérica", essa se insinua no coração do jovem como um fluido que erode lentamente a rocha:

Entretanto não se deixava o passado condenar sem reagir com energia. Uma voz íntima, submissa, vaga, mas incessante como o estalido da filtração que mina gota a gota do coração do rochedo; voz de mofa, importuna e irônica [...]

\section{Granitos e Rochas Primitivas}

Nas obras de José de Alencar a rocha é, quase que invariavelmente, granito. Em seu primeiro romance, Cinco Minutos, os granitos são elementos que dão sublimidade ao cenário carioca:

Mas então a majestade dessas montanhas de granito, a poesia desse vasto seio de mar, sempre alisado como um espelho, os grupos de ilhotas graciosas que bordam a baía, nada disto me preocupava.

O granito também é um elemento que con- 
tribui para a grandiosidade da paisagem em seu segundo romance, A Viuvinha (Alencar 1970a). Prestes a cometer suicídio, Jorge observa a Baía da Guanabara sob o nascer do sol:

Um espetáculo majestoso se apresentava diante de seus olhos; aos toques da luz do sol parecia que essa baía magnífica se elevava do seio da natureza com os seus rochedos de granito, as suas encostas graciosas, as suas águas límpidas e serenas.

São formadas por granitos as elevações das planícies dos pampas em O Gaúcho; a Pedra Bonita em Sonhos D'Ouro e os penhascos abruptos da Serra do Mar que margeiam o Rio Paraíba, em O Tronco do Ipê. Nesses romances, entretanto, a majestade é substituída por uma perspectiva soturna, mais característica de Alencar em relação às rochas. No Boqueirão, palco dos principais acontecimentos em O Tronco do Ipê, o granito forma a lapa da qual se podia divisar a Mãe-d'Água, entidade que atrai à morte os visitantes:

De um lado da bacia notava-se uma grande pedra quadrada em forma de laje, com uma borda levantada à guisa de parapeito, e uma saliência encostada ao rochedo, figurando um divã $[\ldots]$ Ela ficava exatamente na base do mais alto e mais áspero dos rochedos, o qual prolongava sobre o lago uma ponta abrupta semelhante a uma crista. Esse dossel de granito, com suas franjas verdes de parasitas e orquídeas, tornava ainda mais umbroso o rebojo do lago $[\ldots]$

A descrição da lapa com sua "ponta abrupta" em forma de "crista" é mais condizente, entretanto, com afloramentos de gnaisses, rochas frequentes nas margens e nas ilhas ao longo do Rio Paraíba em seu trecho fluminense.

A escolha do granito como "a rocha" em seus romances poderia ser explicada pela sua abundância na cidade do Rio de Janeiro, onde Alencar residiu a maior parte de sua vida. No século dezenove naturalistas estrangeiros descreviam os morros da cidade do Rio de Janeiro como constituídos essencialmente por granitos (Almeida \& Porto Jr. 2012), não só devido à real abundância dessas rochas, como pela composição quartzo-feldspática dos gnaisses a elas associados. Entretanto, é possível que a escolha de Alencar também esteja relacionada ao fato de o granito ter papel central na poesia romântica, na qual era reconhecido como "rocha primitiva", por excelência. Assim, em O Gaúcho, Alencar chama de granitos a rochas que formam as serras que se elevam abruptamente nas planícies dos pampas, ao longo da fronteira entre o Rio Grande do Sul e o Paraná, nas proximidades de Entre Rios. Tanto a localização quanto a morfologia retratada por Alencar indicam tratar-se de elevações constituídas por basaltos. A incorreção poderia ser atribuída ao fato de o autor usar o granito como "rocha padrão" ou não conhecer a área em que se passa o romance, como afirmado por Araripe Júnior, mas também pode resultar de uma opção estética, pois em Til, Alencar demonstra conhecer a natureza distinta do basalto, ao enaltecer a fertilidade do solo formado pela sua alteração, na região entre Atibaia e Piracicaba, ressaltando as características químicas da rocha máfica:

Era acidentado o terreno, que atravessava esse caminho, cortado no maciço de uma mata virgem, tão exuberante, que todos os anos fechava com os renovos da vegetação a picada aberta no inverno. O solo aí, como em toda a cercania, cobre-se de uma crosta da argila roxa, afamada na província por sua espantosa fertilidade. Em verdade, quando se deixa Campinas, e a pata dos animais começa a triturar essa terra ferruginosa, tão fácil de converter-se em pó sutilíssimo como em profundo tremedal, a natureza muda de aspecto; arrea-se de galas, e aos campos tão monótonos, embora célebres, de Piratininga, sucedem os bosques frondosos de Piracicaba.

No final do século dezessete, o termo "primitivo" estava associado às mais antigas rochas do planeta. Eram tipos maciços, desprovidos de fósseis, surgidos nos primórdios da formação da Terra e, portanto, já existentes no período antediluviano. O granito, por ser comumente encontrado nos núcleos das montanhas, seria o tipo mais representativo dentre essas rochas, fato contestado por James Hutton em 1788, que o considerava produto da cristalização de fusões ígneas de idades diversas e não apenas de origem primitiva. As ideias de Hutton foram, posteriormente, adotadas por Charles Lyell em Principles of Geology, livro que alcançou grande popularidade no século dezenove. Os debates a respeito da origem dos granitos não se restringiram à comunidade científica e encontraram eco entre os poetas românticos. Para esses, as rochas primitivas representariam ruínas de um mundo antigo, símbolos de magnitude, mistério e durabilidade (Heringman 2004). José de Alencar não ficou imune a essa influência. Em Sonhos 
D'Ouro, ao comparar as vistas obtidas a partir do Alto da Tijuca, o romancista reconhece dois cenários contrastantes. Enquanto o Vale do Andaraí, no lado continental, apresenta uma paisagem bucólica, de encostas apenas onduladas, o lado que margeia o oceano seria acidentado, exibindo exemplares das rochas mais antigas do planeta:

Na outra face, a natureza é agreste; dir-se-ia uma terra convulsa. $\mathrm{O}$ fogo subterrâneo ferveu nas entranhas da terra, e rasgando-lhe os flancos, arremessou aqui e ali pelas encostas aqueles enormes calhaus ou maciços de rocha, fragmentos da primeira carcaça do globo.

A superfície da terra conserva ainda um aspecto combusto e árido; vê-se que por aí passou a lava em tempos remotos. De espaço a espaço o trabalho do homem cobriu a encosta da montanha de plantações; mas entre esses pontos cultivados destaca-se ainda mais a bronca aspereza dos sítios agrestes.

Essa visão antagônica entre diferentes terremos também ocorre em $\mathrm{O}$ Gaúcho. $\mathrm{Na}$ transição da planície para uma área topograficamente mais acidentada, as coxilhas e os vales são comparados aos contornos de uma mulher e, gradativamente, a harmonia da área mais plana vai sendo substituída pela irregularidade das montanhas de origem primitiva, mais uma vez relacionadas a convulsões:

As formas da campanha se convulsam agora. [...] Sucedem algumas rampas áridas incrustadas de grandes seixos dispersos, estilhaços de primitivas explosões. Afinal levantam-se grandes molhos de esguios alcantis, cobrindo a lomba dos cerros, como híspidas cerdas.

Essa percepção do belo associado à planície e às rochas sedimentares e de desordem associada às áreas mais elevadas produzidas por processos ígneos compactua com o horror às montanhas expresso por poetas britânicos que seguiram a visão estética de Thomas Burnet e, também, com a antipatia de Goethe pelo modelo huttoniano de formação de rochas, expressa no poema Fausto (Goethe 1956, 2011). O desconforto diante da possibilidade de uma origem ígnea e da ocorrência de inversões estratigráficas, expresso em Fausto, é percebido em Til:

Era a furna de Jão Fera. Não tinha essa caverna traços de primitiva formação, quando o fogo subterrâneo vazara o esqueleto granítico daquele fraguedo; nem mesmo provinha de algum aleijão vulcânico, desses que às vezes subvertem as entranhas da terra.

Note-se que, nesse trecho, Alencar utiliza o conceito de rochas primitivas não para registrar um processo, mas para negar-lhe a existência de provas. As rochas "não" tinham traços da primitiva formação, nem sua estratigrafia havia sido invertida por um "aleijão" vulcânico. A seguir, Alencar explica que a moradia de Jão Fera devia sua existência a um processo intempérico iniciado quando uma semente se alojou em uma fenda, posteriormente transformada em árvore. De existência efêmera, a gruta poderia desaparecer a qualquer momento:

Um dia estalou o penhasco; e subitamente escalado, um estilhaço do alcantil rolou sobre a laje. Amparada de um lado pela curva do tronco, e do outro retida por uma aresta da fronteira escarpa, a grande lasca ficou suspensa na altura de alguns pés, formando assim a abóbada da gruta, fechada em torno pelos rochedos abruptos.

A perspectiva sombria em relação às rochas em O Tronco do Ipê é uma constante ao longo de todo o romance. As rochas do Boqueirão, além de abrigar a Mãe-D'Água reforçam a crença local de ser Pai Benedito um bruxo. O termo "áspero" é aplicado às rochas que rodeiam o ex-escravo morador de uma cabana às margens do rio:

$\mathrm{O}$ aspecto disforme do negro, e o isolamento em que vivia naquele sítio agreste em meio de ásperos rochedos, incutiram no espírito da gente da vizinhança a crença de que o Pai Benedito era feiticeiro.

Ojovem Mário, entretanto, enfrenta a natureza soturna resultante da união entre a rocha e a água, união essa capaz de gerar animais horripilantes:

Debalde pululava aí sob aquela vegetação linfáti- 
ca, a geração abundante de medonhos répteis, que produz sempre nos climas tropicais, o consórcio da água profunda com o rochedo cavernoso. [...] mas a luta se travara entre aquele menino audaz e aquele abismo terrível; um deles devia triunfar e vencer o outro, ou o abismo havia de devorar o menino, ou o menino submeteria o abismo e zombaria de sua cólera. / Mário triunfou. Como o rochedo, o lago recebeu seu jugo. Sondou ele as profundidades do boqueirão, e estudou a sua carcaça; com a continuação, chegou a conhecer todos os incidentes do abismo."

Mesmo quando não transmutados em seres vivos, as rochas e as montanhas personificam o lado sombrio da natureza. Em Til, assim Alencar descreve um local popularmente conhecido como Ave-Maria, cujos rochedos escabrosos o tornavam propício a emboscadas:

[...] havia contudo um lugar, cujo torvo aspecto correspondia ao terror supersticioso que inspirava e à sinistra reputação que adquirira.

Pouco além da interseção de outra picada, coleava o caminho algum tempo entre marachões cobertos de arvoredo, e por fim metendo-se pela garganta de um rochedo escabroso, descia em ziguezagues para remontar a oposta rampa de profunda grota.

E em Sonhos D'Ouro, a figura de Guida se destaca sobre um fundo sombrio de rochas, em um dos seus encontros acidentais com Ricardo nos caminhos da Tijuca. A beleza da árvore é substituída pela rocha sombria:

A moldura sim, era diferente; os florões dourados dos corimbos da aroeira foram substituídos pela negra e musgosa cercadura do rochedo.

\section{Dados Empíricos}

José de Alencar também faz uso de dados empíricos de cunho geológico em seus romances. Durante o incêndio que destruiu a casa de Vaz Caminha, em As Minas de Prata, o escritor traz à tona a questão dos polimorfos de carbono para definir os rumos da estória. Estácio atira os diamantes herdados ao fogo, levando-o ao estado gasoso:

Uma lembrança atravessou o espírito de Estácio. Ouvira outrora no pátio uma renhida controvér- sia sobre a combustão do diamante, então simples conjetura dos sábios que só mais tarde foi verificada por experiências repetidas. [...] Encheu Estácio a mão de diamantes e atirou-os sobre aquele pavimento abrasado; umas após outras, lá foram as riquezas que encerrava o misterioso cofre. A todas devorou o incêndio em poucos instantes: o carbônio, que se cristalizara no seio da terra, volatilizou-se ao fogo e derramou-se na atmosfera. Naquela noite, os viventes, que habitavam por aí acerca, respiraram um ar miasmático impregnado dessas exalações milionárias.

Embora o romance esteja ambientado no início do século dezessete, Alencar recorre a experimentos realizados posteriormente para justificar a volatização do mineral.

Analogias com processos de refração da luz ao incidir sobre cristais são recorrentes nos textos de Alencar. Os olhos da onça, em O Guarani, são análogos ao reflexo da luz do sol incidindo sobre cristais:

Ali por entre a folhagem, distinguiam-se as ondulações felinas de um dorso negro, brilhante, marchetado de pardo; às vezes viam-se brilhar na sombra dois raios vítreos e pálidos, que semelhavam os reflexos de alguma cristalização de rocha, ferida pela luz do sol.

Em O Tronco do Ipê, o autor compara as ondas sonoras do canto do sabiá com ondas refratadas por um diamante. Assim como o canto do sabiá se destaca por sua beleza dos demais sons em uma floresta, também a beleza do diamante se sobressai dos demais cristais pela intensidade de sua refração:

Um enxame de passarinhos de diversas cores esvoaçava chilreando entre as laranjeiras; e no meio desse concerto harmonioso, destacava como a rutilação do diamante entre as cintilações do cristal, a nota opulenta e sonora do sabiá;

Ainda em O Tronco do Ipê, raios de luz que incidem em cristais refletem a imagem de Alice no espelho de água do Boqueirão. A combinação entre a imagem refletida e raios de sol refratados resulta em uma ilusão óptica que leva a jovem a afogar-se:

Alice, debruçada sobre o parapeito de pedra, não percebera que fronteira a ela havia na rocha uma face côncava coberta de cristalizações que espelhavam o seu busto gracioso, do qual só a parte superior se refletia diretamente nas águas. / Esse busto refrangido pela rocha, e reproduzido pela tona do lago, apresentou aos olhos de Ali- 
ce a sombra ainda vaga da mãe-d'água. Depois, quando uma réstia de sol esfrolou-se em espuma de luz sobre a fronte límpida da menina, e um raio mais vivo cintilando nas largas folhas úmidas da taioba, lançou as reverberações da esmeralda sobre os louros cabelos, o busto se debuxou e coloriu. / Tudo o mais foi efeito da vertigem causada pela fascinação. $\mathrm{O}$ torvelinho das águas produz na vista uma trepidação que imediatamente se comunica ao cérebro.

Por fim, a ascendência da alma de Alice, considerada morta, dá-se por um processo de polarização de luz:

A cútis alva tinha uma doce transparência produzida pela polarização da luz de sua alma que se refrangia para o céu.

Em Til, as propriedades refratárias do diamante são empregadas de forma extremamente poética para ilustrar a capacidade de Berta de lidar com situações e tipos humanos incomuns. Berta, assim como o diamante, é multifacetada:

Nesse prisma da lindeza de Inhá reflete-se a sua índole. Aquela alma tem facetas como o diamante; iría-se e acende uma cor ou outra, conforme o raio de luz que a fere.

\section{Geologia Estética: influências britânicas sobre Alencar}

No prefácio de Sonhos D'Ouro, escrito quinze anos após a publicação de seu primeiro romance, José de Alencar apresentou um projeto de integração de sua obra em um conjunto que, segundo sua perspectiva, poderia ser dividido em três fases: a Primitiva, a Histórica e a que chamou de Infância de Nossa Literatura. Haveria entre essas uma linha unificadora que ligaria romances de várias épocas, à semelhança do sistema concebido por Honoré de Balzac, motivo pelo qual o projeto foi criticado como uma tentativa de imitação do escritor francês que, assim como Alencar, somente em meio à Comédia Humana teria criado um plano de unificação de sua obra (Proença 1966). Além de Balzac, diversos escritores são apresentados como prováveis modelos para as criações de Alencar: Alexandre Dumas, Saint-Pierre, Chateaubriand, Walter Scott, Fenimore Cooper, Frederich Marryat, Garret, George Ohnet, George Sand, Joaquim
Manuel de Macedo, Lamartine, Manzoni e Abade Prevost. Segundo Proença (1966), o grande número de supostas influências apenas atesta a vasta cultura literária do escritor brasileiro.

Flankin Távora o considerava um imitador do americano Fenimore Cooper (Tavora 2011), fato negado por Alencar que afirmou não haver semelhanças de temas, gênero ou estilo entre suas obras e as do autor americano, enfatizando o fato de Walter Scott ter antecedido Cooper na utilização da natureza como elemento fundamental da narrativa (Alencar 2005). A sua admiração por Scott vinha, segundo o próprio Alencar, do período em que era estudante em São Paulo e gastava suas economias, durante as férias no Rio de Janeiro, na assinatura de um gabinete de leitura da Rua da Alfandega, onde tinha acesso tanto às edições de Scott, como aos livros de Cooper. Segundo Alencar, sua percepção poética da natureza não sofria de nenhuma influência literária dominante, mas teria se manifestado na infância, quando viajou com a família do Ceará e Bahia. Seu mestre teria sido a "natureza do Brasil".

Entretanto a influência de Scott na obra de Alencar pode ser reconhecida em vários romances. Proença (1966) aponta semelhanças entre a composição dos personagens e as cenas de ação em $A s$ Minas de Prata e Ivanhoé e, assim como nas obras do escritor escocês, o passado histórico é idealizado pelo escritor brasileiro como um momento heroico, lendário, no qual a natureza ocupa um papel essencial na composição dos personagens e do enredo (Candido 1969). No caso do uso estético de elementos geológicos, a influência de Scott e de outros autores britânicos é patente. Apesar de apresentar a natureza brasileira como sua principal fonte de inspiração, notam-se nas obras de Alencar elementos que extrapolam a paisagem brasileira. "Negras cavernas", "abismos infernais", "rochas alcantiladas", "profundezas das montanhas", "cavernas cavadas em rochas vivas, muito tempo antes da criação" são termos e expressões encontradas, por exemplo, em O Talismã, obra de 1825 (Scott 1920), com correspondentes na obra de Alencar.

Walter Scott foi contemporâneo de Hutton. Ambos frequentavam os mesmos círculos sociais e científicos e o novelista acompanhou a controvérsia envolvendo plutonistas e netunistas, tendo mesmo ocupado a presidência da Royal Society of Edinburgh entre 1820 e 1832. Ao viajar para Edimburgo, Guy Mannerin, personagem central do romance homônimo publicado pelo autor escocês em 1815 (Scott 1968, sem data a, sem data b), leva consigo cartas de 
apresentação para encontrar-se com nove pessoas eminentes do iluminismo escocês - David Hume, John Home, Adan Ferguson, Joseph Black, Lord Kames, Jonh Clerk, Adam Smith, William Robertson e... James Hutton. Curiosamente, na única tradução para português disponível dessa obra, atribuída a K. Avellar (edição sem data, anterior a 1940 segundo registros manuscritos nos volumes consultados neste trabalho), o nome de Hutton, e apenas o dele, é omitido dentre os iluministas citados.

Não apenas Scott, mas vários autores considerados influentes nas obras de Alencar, como Byron, Sand, Goethe e Dickens, tiveram trajetórias literária com conexões diretas com as grandes descobertas geológicas de sua época. Em Cinco Minutos, são encontrados ecos do Poema Caim, um drama de Lord Byron sobre a história da evolução natural da Terra inspirado nas teorias catastrofistas de Cuvier. Após saber da doença mortal de sua amada Carlota, o personagem/narrador de Cinco Minutos deseja encontrar,

[...] no universo algum lugar desconhecido, algum canto de terra ainda puro do hálito do homem, onde a natureza virgem conservaria o perfume dos primeiros tempos da criação e o contato das mãos de Deus quando a formara.

e parte em uma corrida contra o tempo para encontrar a amada, comparando si mesmo a uma rocha que

[...] colocada em um dos cabeços da montanha tinha-se desprendido de seu alvéolo secular e, precipitando-se com todo o peso, rolava surdamente pelas encostas. / O galopar do meu cavalo formava um único som, que ia reboando pelas grutas e cavernas e confundia-se com o rumor das torrentes.

A última frase apresenta função puramente estética, pois o personagem percorria o trajeto entre o Rio de Janeiro e Porto de Estrela, localizado no fundo da Baía da Guanabara, trajeto esse sobre terrenos quaternários e no qual inexistem grutas ou cavernas. A seguir, Alencar deixa clara sua fonte de inspiração, quando o jovem, no intuito de instigar seu cavalo a correr com mais velocidade lhe sussurra a ouvido "a palavra de Byron: - Away!".

Assim como os românticos europeus, Alencar faz uso de imagens metafóricas envolvendo vulcões e terremotos, desconsiderando a inexistência desses fenômenos em terras brasileiras. No capítulo final de O Gaúcho, onde Alencar descreve os efeitos provocados na paisagem pela passagem de um tufão, a imagem apresentada é, em sua essência, a descrição de uma erupção vulcânica:

Parecia que a terra arquejava com o estertor de um pesadelo. / Ao mesmo tempo uma exalação ardente como o vapor de uma cratera derramou-se pela solidão. [...] Os dois cavalos, com o pêlo eriçado, resfolgavam aquele bafo ígneo, semelhante ao fumo de uma batalha [...]

E nesse quadro, enquanto os raios se assemelham a derrames de lava, os sedimentos carreados pelo tufão são espalhados pelo ar, escurecendo o céu como as cinzas de um vulcão:

De repente a lua sepultou-se. Céu e terra submergiram-se num oceano de trevas. $\mathrm{O}$ aluvião das procelas se arremessara do horizonte e inundara a imensidade do espaço. [...] Afinal ribombou o trovão na vasta abóbada negra, sobre a qual o relâmpago despejava cataratas de chamas.

As palavras "terremotos", "vulcão" e "lava", embora representem uma natureza não vivenciada por Alencar, eram frequentes na poesia romântica vitoriana, cuja admiração por parte do escritor brasileiro é confirmada em sua autobiografia, na qual revela ter passado parte de sua adolescência a "baironizar", escrevendo poemas nas paredes de seu quarto quando estudante em São Paulo, em um período em que os jovens paulistas não só cultuavam Byron, mas também procuravam lhe imitar o estilo de vida (Alencar 2005, Broca 1981).

Nota-se, contudo, que apesar de o uso estético de elementos geológicos já estar presente em seus primeiros romances, este era casual, tornando-se mais frequente e ganhando relevância a partir da publicação de As Minas de Prata. O romance, publicado entre 1865 e 1866, reconstitui a história de bandeirantes em busca das lendárias minas de prata sul-americanas, culminando com a descoberta de diamantes na Chapada Diamantina. O tema, por si só, é favorável à inserção de componentes geológicos. Contudo, os elementos geológicos são inseridos tardiamente, surgindo apenas a partir da metade do enredo d'As Minas. É nos romances publicados posteriormente (O Gaúcho, 1870; O Tronco do Ipê, 1871; Til, 1871 e Sonhos D’Ouro, 1872) que as rochas e os fenômenos geológicos ganham maior expressão poética e se tornam mais frequentes. Os 
dois primeiros fascículos d'As Minas De Prata foram lançados em 1862 e os cinco últimos volumes do romance foram escritos em apenas três meses em 1864, ano de seu casamento (Proença 1966). A valorização da geologia como componente estético coincide, portanto, com início da convivência de José de Alencar com a família de origem escocesa de sua futura esposa, Georgina Cochrane, não sendo improvável ter Alencar aprofundado seu interesse pelo tema por influência de sua nova família.

Após ter iniciado As Minas da Prata, Alencar foi obrigado a interromper o trabalho por problemas de saúde e, aconselhado por seu médico, buscou repouso no Hotel Bennet, na Tijuca. Em uma das caminhadas matinais, teve seu primeiro contato com o médico escocês Thomas Cochrane, proveniente de uma família que, tradicionalmente, valorizava tanto a cultura literária como científica. O médico era primo-irmão do Almirante Thomas Cochrane, ex-comandante da Armada Imperial Brasileira, e sobrinho de Archibald Cochrane, inventor, contemporâneo de Hutton, membro da Royal Society of Edinburgh e colaborador direto de James Watt e Joseph Priestley.

Bacharel em Letras pela Universidade da França e médico pela Universidade de Londres, Thomas Cochrane foi membro fundador da Academia Homeopática do Brasil e possuía um laboratório de manipulação de receitas homeopáticas. Em 1840 havia obtido concessão para construir a estrada de ferro que ligaria o Rio de Janeiro a São Paulo e, nos doze anos que se seguiram, constituiu família e trabalhou na realização do projeto ferroviário, que não se concretizou, em parte por questões burocráticas e instabilidades políticas. Apesar do fracasso do projeto da linha Rio-São Paulo, em 1858 Cochrane obteve a concessão da primeira linha de bondes da cidade do Rio de Janeiro, projetada para chegar ao Alto da Boa Vista, nas serras da Tijuca, local de sua residência (Azevedo 1965).

A Tijuca, nesse período, era o lugar de moradia preferido dos britânicos no Rio de Janeiro, motivo pela qual o local era chamado por Alencar de "Escócia Brasileira" (Gadelha 2001). A família Cochrane possuía uma chácara em meio às matas tijucanas, no local hoje conhecido como Morro do Cochrane, onde Alencar teria escrito Sonhos D'Ouro, O Sertanejo e o Tronco do Ipê. (Menezes 1965). O sítio é referenciado em Sonhos D’Ouro, romance inspirado em seu romance com Georgina e que permite vislumbrar quais seriam os hábitos e temas de interesse da família escocesa à qual Alencar se uniu pelo matrimônio. No romance, Alencar declara a supremacia dos britânicos em relação ao conhecimento sobre rochas, ao discorrer sobre as serras da Tijuca:

Se quereis ver o que há de mais belo e encantador naquele arrabalde, procurai o conhecimento de algum filho da Grã-Bretanha. Ele conhece a Tijuca de uma à outra extremidade, desde a gruta mais funda até o pico mais alto. Sabe não só dos vários passeios, como do dia e da hora em que se deve apreciar cada um deles. Afinal, quando tiverdes visto toda a Tijuca já descoberta e explorada, o inglês inventará uma pedra ainda não conhecida e uma excursão pitoresca como a de subir à Gávea por um caminho de lagarto.

E ainda,

A Pedra Bonita é uma rocha que se levanta sobre um cabeço de montanha como um gorro de granito. [...] Como todos os belos sítios da Tijuca, a Pedra Bonita é muito frequentada pelos filhos da loura Álbion, incansáveis exploradores desse belo arrabalde do Rio de Janeiro. Contam que um inglês aí se perdera, ficando sobre o gigantesco pedestal de rocha, elevado à condição de estátua, durante três dias, sem comer nem beber. Foi-lhe o penedo o contrário do outeiro da Ilha dos Amores: mais fácil de subir que de descer.

O interesse de Thomas Cochrane por geologia não seria apenas diletante, mas ligado a seus assuntos profissionais. Como médico e proprietário de um laboratório homeopático, Cochrane manipulava diversos compostos minerais que estão listados em seu livro Medicina Domestica Homoeopathica (Cochrane 1868a,b). Como empresário ele havia realizado, em 1838, uma jornada com o engenheiro Barão de Schneéburg com objetivo de analisar os terrenos a serem cortados pela futura ferrovia e avaliar questões técnicas relacionadas a transposição da Serra do Mar (Azevedo 1965).

O irmão mais velho de Georgina, Ignácio Cochrane, filho do inglês e também médico, Wallace MacFarlane, formou-se em engenharia na Escola Militar do Império do Brasil, onde estudou entre 1853 e 1857. Quando aluno do Curso de Engenharia na Escola Militar, cursou as cadeiras de "Química e Mineralogia" e "Geologia, Montanística e Metalurgia”. Juntas, estas disciplinas compunham quinze por cento do total de matérias da grade curricular. Posteriormente, Ignácio Cochrane teve importante participação na construção da Estrada 
de Ferro São Paulo Railway, dando continuidade às expectativas do padrasto (Azevedo 1965).

Portanto, além da bagagem cultural e científica, o envolvimento dos Cochranes com projetos ferroviários, então nascentes no Brasil, torna plausível a hipótese de que estes possuíssem ou tivessem acesso a obras dedicadas a questões geológicas.

A questão que aqui se apresenta é: teria José de Alencar acessado textos geológicos, como a obra de Lyell? Assim como Dickens e George Sand, poderia o autor brasileiro ter encontrado inspiração em Principles? Ou sua perspectiva romântica teria como inspiração apenas obras literárias de cunho artístico?

Em seus textos, Alencar demonstra ter acessado obras de naturalistas europeus. Tal pode ser comprovado, por exemplo, no primeiro capítulo de $O$ Tronco do Ipê, quando, ao desmitificar um fenômeno aparentemente sobrenatural, Alencar apresenta argumentos geológicos para explicar a existência de vozes que vinham das entranhas da terra:

Além de confirmar a primeira observação, conheci que a voz era a do preto, e transmitia-se por um fenômeno natural proveniente da construção geológica do sitio. Seguindo a direção que tomara o pai Benedito, fui achá-lo metido em uma espécie de furna que havia no rochedo, inclinado ou quase caído de bruços sobre uma pedra úmida, coberta de limo e parasitas.

Ainda em O Tronco do Ipê, Alencar faz menção a Cuvier e Buffon em uma cena cômica onde Domingo Pais se vê diante da difícil tarefa de destrinchar um pato:

Condenado a trinchar em todos os banquetes esse palmípede, o Sr. Domingos Pais suava pelo topete antes de acertar com as juntas da asa ou da coxa. Em sua opinião, mais adiantada que Buffon e Cuvier, o pato era um animal inteiriço, feito de um só osso.

Buffon também é mencionado em O Gáucho quando discorre sobre a classificação dos tipos de relinchos do cavalo.

A palavra convulsão, tantas vezes utilizada por Alencar, repete-se por mais de sessenta vezes ao longo do livro de Lyell, enquanto a expressão "fogo subterrâneo", usada para descrever a gruta de Jão Fera, em Til, é frequente em Principles. De fato, uma das frases utilizada por Alencar em Til possui uma construção semelhante às utilizadas por Lyell. Em Til lê-se:
Não tinha essa caverna traços de primitiva formação, quando o fogo subterrâneo vazara o esqueleto granítico daquele fraguedo.

Em Principles of Geology, Volume 1:

Rocks, also produced by subterranean fire in former ages at great depths in the bowels of the Earth [...]

[...] volcanic rocks, formed in our own time in the bowels of the Earth, whether in rents and caverns [...]

O livro de Charles Lyell era a principal referência nos estudos de geologia no século dezenove sendo admissível que a obra circulasse no Rio de Janeiro nesse período. O Catálogo do Acervo da Biblioteca Fluminense, publicado em 1866, mostra que, nesse ano, a instituição possuía uma edição francesa de Principles, datada de 1837 (Biblioteca Fluminense 1866). Atualmente, a Biblioteca Nacional possui uma edição de 1838 , em francês, além de uma edição de L'anciennete de l'homme prouvee par la geologie, também da autoria de Lyell. O Real Gabinete Português de Leitura, também no Rio de Janeiro, exibe um total de sete obras de Lyell. São três edições inglesas de Principles, uma das quais sem o ano de publicação e as demais datadas de 1843 e 1872; uma obra em dois volumes $(1843,1848)$, em francês, pertencentes, originalmente, ao escritor João do Rio; um volume de 186? (data não visível); um volume de The geological evidences of the antiquity of man, de 1873 e, por fim, uma versão em francês da mesma obra, de 1870. O catálogo do acervo da British Subscription Library de 1864, biblioteca que que atendia a comunidade britânica do Rio de Janeiro no período, lista um volume de Principles, sem data de edição (British Subscription Library 1864).

Embora não seja possível determinar o grau de influência das obras científicas sobre os textos de Alencar, há indícios de que esses tenham tido um papel importante em suas composições. Como observado por Candido (1969), naquele período existia um "realismo dos românticos" ao qual correspondia " um patente romantismo dos naturalistas" e como demonstrado por Nicolson (1994) a "geomania" não era um fenômeno individual, mas social. Até mesmo Araripe Júnior que, em seu Perfil Literário de José de Alencar, condenava o romantismo de Alencar, utilizou em suas críticas analogias poéticas envolvendo geologia. Ao discorrer sobre a utilização, por parte de Alencar, 
de escritores americanos como modelo para suas obras, Araripe afirma:

Do mesmo modo que o químico luta para tirar do carvão a diminuta parcela do diamante, ele (Alencar) empregava todos os esforços para uma cristalização ainda mais admirável, a da própria alma.

E segue comparando as diversas influências literárias sobre a obra de Alencar a depósitos estratificados:

Como na crosta de um terreno em formação recente, ali encontra-se a história primitiva de todas as camadas que se foram depositando à lava primitiva e com ela se amalgamaram.

\section{Considerações Finais}

O uso de elementos geológicos é encontrado desde as primeiras publicações de José de Alencar, nas quais é possível detectar influência dos poetas românticos adeptos do pensamento de Thomas Burnet. Entretanto, a poesia romântica parece não ter sido a única fonte de inspiração para a geologia estética de Alencar. Referências a dados empíricos indicam que suas leituras não se limitavam ao universo poético e ficcional, mas também incluíam textos científicos de conteúdo geológico.

Embora já presente nos três primeiros romances do autor, é a partir da publicação de As Minas da Prata, entre 1865 e 1866, que a geologia ganha relevância em seus livros, ou seja, logo após seu casamento com Georgina Cochrane. É improvável que uma família escocesa educada, amante das montanhas e da ciência, liderada por um médico que também era bacharel em letras, não tivesse como tema de suas conversações, mesmo que ocasionalmente, tanto os poemas românticos que abordam questões geológicas como as obras de seus compatriotas, James Hutton e Charles Lyell.

O uso, por parte de Alencar, de termos e expressões comuns em Principles e a frequência com que se serviu da imagem do vulcão como metáfora sugerem conhecimento da obra de Lyell que, como visto, circulava no Rio de Janeiro durante o século dezenove. O fato de o escritor carioca João do Rio possuir a obra, doada à Biblioteca Nacional após a sua morte, demonstra que, assim como na Europa, o livro de Lyell teve repercussão além do círculo científico também no Brasil.
O vulcão como metáfora de emoções ocultas é uma imagem contundente na obra de José de Alencar. Na visão do romancista, assim como o magma reprimido sob o vulcão, as emoções contidas podem aflorar subitamente e com violência. O vulcão de Alencar não é belo, mas símbolo de sentimentos moralmente condenáveis. Representa a ambição de Molina, a revolta de Inesita, o desejo sexual de Jão Fera, Manuel Canho e Ricardo, a cólera do Capitão Gonçalo e a dor de Estácio. Ao perceber o vulcão como imagem de inquietação moral e espiritual Alencar se diferencia dos poetas românticos europeus que tinham como mote principal a problemática do tempo geológico. Para esses, a existência de ciclos que se processavam por tempo indefinido e a extinção de seres vivos geravam dúvidas sobre o papel do ser humano como protagonista do universo, revelando sua fragilidade e ensejando questões sobre os desígnios Divinos. Em Alencar, porém, são as inquietações morais que se sobressaem. Assim como o vulcão simboliza emoções impróprias, as rochas e as montanhas, quando personificadas, estão quase que invariavelmente associadas a termos de conotação negativa em consonância com poetas britânicos que seguiram a linha de pensamento de Thomas Burnet.

Em algumas situações, Alencar concebe às imagens uma fisionomia nativa. Assim, enquanto o megalossauro de Dickens anda pelas ruas de Londres, em A Casa Soturna, em O Tronco do Ipê o monstro antediluviano é transmutado em uma jiboia, uma imagem mais próxima do imaginário nacional e que se repete como metáfora em outros romances.

$\mathrm{Na}$ controvérsia entre netunistas e plutonistas, os sentimentos de Alencar se alinham com as opiniões de Goethe que manifestou no poema Fausto (Goethe 1956, 2011) sua repulsa diante de evidências que comprovariam a teoria plutônica. A paisagem consequente da ação de um "fogo subterrâneo" capaz de "subverter as entranhas da terra" é, segundo José de Alencar, árida, bronca e áspera. $\mathrm{O}$ romancista não nega as ideias propagadas por Hutton e Lyell, mas assim como Goethe, lhe repugna uma Terra forjada pelo fogo.

Por fim, é importante destacar que as passagens envolvendo fenômenos geológicos na obra de Alencar superam, em número, as inserções de mesma natureza feitas por vários ficcionistas europeus tidos como exemplos de autores influenciados pelas discussões geológicas. Isso ocorre porque, entre os europeus, foi na poesia, e não na prosa, que a 
geologia estética teve sua maior expressão. Alencar, contudo, exercia a poesia em prosa, como demonstra Melo (1972) em seu estudo sobre a musicalidade dos textos alencarianos. O romancista fazia uso de unidades melódicas, com ritmo e acentuação poética, o que o torna, assim como os poetas, um escritor de difícil tradução. Esse seu estilo foi a razão de muitas das críticas por parte de seus contemporâneos, que lhe atribuíam o uso incorreto das palavras. A estes, Alencar apresenta, no pós-escrito de Diva, uma justificativa construída, mais uma vez, a partir de uma analogia geológica (Alencar 1970m):

Criar termos necessários para exprimir os inventos recentes, assimilar-se aqueles que, embora oriundos de línguas diversas, sejam indispensáveis; e sobretudo explorar as próprias fontes, veios preciosos onde talvez ficaram esquecidas muitas pedras finas; essa é a missão das línguas cultas e seu verdadeiro classicismo.

\section{Referências}

Alencar J. 1970a. A Viuvinha. Cinco Minutos. A Pata da Gazela. São Paulo: Edigraf. 217p.

Alencar J. 1970b. O Gaúcho. Romance Brasileiro. São Paulo: Edigraf. 254p

Alencar J. 1970c. O Tronco do Ipê. São Paulo: Edigraf. 234p.

Alencar J. 1970d. Sonhos D’Our. São Paulo: Edigraf. 226p.

Alencar J. 1970e. Iracema. Ubirajara. São Paulo: Edigraf. $193 \mathrm{p}$.

Alencar J. 1970f. O Sertanejo. São Paulo: Edigraf. 303p.

Alencar J. 1970g. O Guarani. São Paulo: Edigraf. 370p

Alencar J. 1970h. As Minas de Prata. Tomo I. São Paulo: Edigraf. 267p.

Alencar J. 1970i. As Minas de Prata. Tomo II. São Paulo: Edigraf. 270p.

Alencar J. 1970j. As Minas de Prata. Tomo II. São Paulo: Edigraf. 279p.

Alencar J. 19701. Til. São Paulo: Edigraf. 251p.

Alencar J. 1970m. Lucíola. Diva. Encarnação. São Paulo: Edigraf. $334 \mathrm{p}$

Alencar J. 2005. Como e porque sou romancista. Campinas: Pontes Ed. 76p.

Almeida S. \& Porto Jr. R. 2011. O reconhecimento de cantarias e pedreiras históricas do Rio de Janeiro como elementos estimulantes ao estudo e divulgação das ciências geológicas. Revista Terrae Didatica. 8(1):3-23.

Araripe Júnior T.A. 1989. Luizinha / Perfil Literário de José de Alencar. Rio de Janeiro: Livraria José Olympio Ed. 238p.

Azevedo A. 1965. Cochrane do Brasil. São Paulo. Companhia Ed. Nacional. 339p

Bacon F. 1999. Novum Organum ou Verdadeiras Indicações
Acerca da Interpretação da Natureza. Nova Atlântida. José Trad. Aluysio Reis de Andrade. São Paulo: Ed. Nova Cultural. 255p.

Biblioteca Fluminense. 1866. Catálogo de Livros. Rio de Janeiro: Typographia Thevenet \& C. 312p.

British Subscription Library. 1864. A catalogue of books in the Rio de Janeiro Library. London: L. Smith, Elder \& Co. 85 p.

Broca B. 1981. Alencar: Vida, Obra e Milagre. In Ensaio da Mão Canhestra. Obras reunidas. São Paulo: Ed. Camuru. 318p.

Buckland A. 2013. Novel Science. Fiction ans the invention of nineteenth-century geology. Chicago: The University of Chicago Press. 377 p.

Burnet T. 1961. The Sacred Theory of the Earth. Carbondale. Southern Illinois Univ. Press. 412p.

Cadbury D. 2000. The Dinosaur Hunters: A True Story of Scientific Rivalry and the Discovery of the Prehistoric World. London: Fourth Estate. 374p.

Candido A. (1969). Os Três Alencares. 221-235. In Formação da Literatura Brasileira (Momentos Decisivos). $2^{\circ}$ volume (1836-1880). $3^{\text {a }}$ edição. São Paulo: Ed. Libraria Martins. 440 p.

Cochrane T. 1868a. Medicina Domestica Homoeopathica, ou, Guia pratica da arte de curar homoeopathicamente: contendo tudo quanto ha de mais util que se pode encontrar nos autores homoeopathas. Volume I. $5^{\mathrm{a}}$ ed. Rio de Janeiro: (sem editor). 840p.

Cochrane T. 1868b. Medicina Domestica Homoeopathica, ou, Guia pratica da arte de curar homoeopathicamente: contendo tudo quanto ha de mais util que se pode encontrar nos autores homoeopathas. Volume II. $5^{\mathrm{a}}$ ed. Rio de Janeiro: (sem editor). $780 \mathrm{p}$.

Darwin E. 1825. The Botanic Garden, a poem, in two parts, containing the economy of vegetation, and the loves of the plants, with philosophical notes. London: Jones \& Company. 348p.

Dickens C. 1986. A Casa Soturna. Tradução de Oscar Mendes. Rio de Janeiro: Ed. Nova Fronteira. 822p.

Gadelha M. 2001. José de Alencar. Fortaleza: Edições Demócrito Rocha. 101p.

Goethe J.W. 1956. Fausto. Tradução de Antônio Feliciano de Castilho. São Paulo. W. Jackon Inc. Ed. 319p.

Goethe J.W. 2011. Fausto II. Trad. Jenny Klabin Segall. São Paulo. Ed. 34. 671p.

Heringman N. 2004. Romantic Rocks, Aesthetic Geology. Ithaca: Cornell University Press. 304p.

Lyell C. 1997. Principles of Geology. 1830-1833. London: Penguin Books. 472p.

Melo G.C. 1972. Alencar e a Língua Brasileira. 3a edição. Rio de Janeiro. Conselho Federal de Cultura. Depto. Imprensa Nacional. 143p.

Menezes R. 1965. Cartas e Documentos de José de Alencar. São Paulo. $2^{\mathrm{a}}$ ed. Ed. Hucitec. 181p.

Nicolson M.J. 1997. Mountain Gloom and Mountain Glory. The development of the aesthetics of the infinite. Seatle: Univ. Washington Press. 403p. 
O'Connor R. 2007. The Earth on Show. Fossils and the poetics of popular Science, 1802-1856. Chicago: The Univ. Chicago Press. 541p.

Proença M.C. 1966. José de Alencar na Literatura Brasileira. Rio de Janeiro: Ed. Civilização Brasileira. 147p.

Scott W. 1868. Guy Mannering. Two volumes in One. Boston: Ticknor and Field. Cambridge Univ. Press. Welch, Bigelow and Cia. 33 p.

Scott W. O 1920. Talisman ou Ricardo na Palestina. . Rio de Janeiro - Paris: Livraria Garnier. 444p.
Scott W. O. (sem dataa) Guy Mannering ou o Astrólogo. Tomo I. Rio de Janeiro: Ed. H. Garnier. Paris. 328p. Scott W. O. (sem datab) Guy Mannering ou o Astrólogo. Tomo II. Rio de Janeiro: Ed. H. Garnier. Paris. 297 p.

Távora F. 2011. Cartas a Cincinato. Estudos críticos por Semprônio. Org. Eduardo Vieira Martins. Campinas: Ed. Unicamp. 278p.

Viana Filho L. 1979. A Vida de José de Alencar. Rio de Janeiro: Livraria José Olympio Ed. 311p.

Resumo: José de Alencar, principal nome do movimento literário romântico no Brasil, viveu entre 1829 e 1877, período em que a Geologia se consagrou como ciência e se tornou assunto de interesse também fora da comunidade cientifica. 0 escritor brasileiro não ficou insensível às questões geológicas e ao longo de sua obra são encontrados vários exemplos de Geologia Estética, que se torna mais relevante a partir de seu casamento com Georgina Cochrane, pertencente a uma família escocesa admiradora das montanhas e de sólida formação literária e científica. A personificação de rochas e montanhas e a utilização de vulcões como metáforas de sentimentos ocultos são as expressões mais contundentes nos romances de Alencar; suas visões estão em acordo com a percepção sombria manifestada por Thomas Burnet e pelos poetas britânicos em relação às rochas. Para Alencar, 0 granito é a "rocha" por excelência e, assim como Goethe, o escritor demonstra desconforto diante do modelo plutonista defendido por Hutton e Lyell.

Palavras Chaves: José de Alencar, Geologia Estética, história da Geologia, literatura brasileira. 